\title{
Physicomechanical and thermal analysis of bulk-fill and conventional composites
}

\author{
Armiliana Soares NASCIMENTO(a) \\ José Filipe Bacalhau RODRIGUES(b) \\ Rodolfo Henrique Nogueira \\ TORRES $^{(b)}$ iD \\ Kleilton Oliveira SANTOS(b) \\ Marcus Vinicius Lia FOOK ${ }^{(b)}$ \\ Monica Soares de ALBUQUERQUE(a) iD \\ Eliane Alves de LIMA $^{(a)}$ iD \\ Pedro Tardelly Diniz FILGUEIRA(a) \\ João Batista Morais dos SANTOS(b) iD \\ Leonardo Jose Rodrigues de \\ OLIVEIRA(a) $^{(a)}$ \\ Rodivan BRAZ(a) \\ (a) Universidade de Pernamburco - UPE, \\ Department of Dentistry, Tabatinga \\ Camarajibe, PE, Brazil. \\ (b) Universidade Federal de Campina Grande - \\ UFCG , Department of Materials Science and \\ Engineering, Campina Grande, PB, Brazil.
}

Declaration of Interests: The authors certify that they have no commercial or associative interest that represents a conflict of interest in connection with the manuscript.

Corresponding Author:

Armiliana Soares Nascimento

E-mail: armiliana@hotmail.com

hitps://doi.org/10.1590/1807-3107bor-2019.vol33.0008

Submitted: May 25, 2018

Accepted for publication: November 26, 2018

Last revision: January 09, 2019
Abstract: The aim of this study was to evaluate the degree of conversion (DC) and the thermal stability of bulk-fill and conventional composite resins. Eleven composite resin samples were prepared to evaluate the DC, Vickers microhardness (VMH), mass and residue/particle loss, glass transition temperature (Tg), enthalpy, and linear coefficient of thermal expansion (CTE) using infrared spectroscopy (FTIR), microdurometer analyses, thermogravimetric analysis (TGA), differential scanning calorimetry (DSC), and dilatometry (DIL). The data were subjected to statistical analysis, with a significance level of $95 \%$. DC and VMH were not influenced by the polymerized side of the sample, and statistical differences were recorded only among the materials. Decomposition temperature, melting, and mass and residue loss were dependent on the material and on the evaluation condition (polymerized and non-polymerized). Tg values were similar between the composites, without statistically significant difference, and CTE ranged from 10.5 to $37.1\left(10^{-6} /{ }^{\circ} \mathrm{C}\right)$, with no statistical difference between the materials. There was a moderate negative correlation between CTE and the $\%$ of load particles, by weight. Most resins had a DC above that which is reported in the literature. TGA, $\mathrm{Tg}$, and CTE analyses showed the thermal behavior of the evaluated composites, providing data for future research, assisting with the choice of material for direct or semidirect restorations, and helping choose the appropriate temperature for increasing the DC of such materials.

Keywords: Dental Materials; Composite Resins; Transition Temperature; In Vitro Techniques.

\section{Introduction}

Composite resins have been widely used in the restoration of anterior and posterior teeth. Conventional techniques use increments of up to $2 \mathrm{~mm}$ to allow for adequate polymerization and to avoid adverse reactions in the postoperative period. Nevertheless, the incremental insertion technique can cause inconveniences such as polymerization shrinkage inherent in the curing process of methacrylate-based composites, eventually leading to dental cracks, marginal leakage, and postoperative sensitivity. ${ }^{1}$ In order to optimize restorative procedures in posterior teeth, bulk-fill resins emerged with the single-step incremental insertion proposal, ranging 
from 4 to $6 \mathrm{~mm}^{2}$ in thickness, or two-step insertion, considering a bulk-fill flow for the base, covered with a restorative resin. ${ }^{2}$ Thus, the use of these materials in clinical practice considerably decreases chair time in direct restorations of posterior teeth. ${ }^{3}$

Bulk-fill resins been used in clinical applications worldwide, especially because of favorable scientific have evidence concerning their effectiveness. The literature points out numerous studies showing that bulk-fill resins offer better usage conditions, ${ }^{4}$ and this is associated with the use of new fillers or possibly photoinitiators, which contribute to increasing translucency, allowing greater penetration of light; ${ }^{5}$ with the use of rheological modulators, which minimize polymerization shrinkage stress; ${ }^{6}$ with the insertion of a high viscosity material aided by the emission of sonic waves, which increases fluidity and improves marginal adaptation, ${ }^{7}$ with the modification of the inorganic phase using reinforcement fibers, applied to some bulk-fill material, which provides restorations with greater resistance. ${ }^{8}$

Regarding physicochemical and thermal properties, there is much to study and research, so that we can have scientific evidence about the most suitable composite to be chosen for direct or semidirect restorative procedures. Application of heat is an additional method used to increase the physicomechanical properties of composites. The heat assists in the final degree of conversion (DC), reduces polymerization shrinkage stress, acts as a homogenizer, and improves the mobility of monomers. ${ }^{9}$ On the other hand, when resins are heated until they reach $\mathrm{Tg}$ and undergo a slow cooling process, the polymer chains have more time to settle in an orderly and more compact way, favoring hardness properties. However, in the mouth, resins must have low thermal conductivity in order to prevent damage to the pulp tissues and a coefficient of thermal expansion (CTE) similar to that of the dental structure to prevent loss of adhesion, crevice formation, marginal infiltration and, consequently, secondary caries.

Given the innovative nature of bulk-fill composites, the short length of time they have been available in the market, and the paucity of long-term clinical studies, ${ }^{10}$ the objective of this study was (a) to evaluate
DC using FTIR and Vickers microhardness (VMH); (b) to evaluate degradation and thermal stability considering the extrapolated onset temperature, mass loss, and the weight percent of load particles using thermogravimetric analysis (TGA); (c) to determine glass transition, melting, and degradation temperatures, and enthalpy using differential scanning calorimetry (DSC); and (d) to evaluate the linear coefficient of thermal expansion (dilatometry).

The null hypotheses tested were as follows: a) the DC and VMH would not be influenced by the polymerized side of the sample and between the materials; v) degradation and thermal stability would not depend on the material and on the evaluation condition; c) there would be no significant differences in the CTE between the evaluated materials.

\section{Methodology}

\section{Materials and sample preparation}

Eleven resins (Table 1) were evaluated in this study: nine bulk-fill composites -Aura Bulk Fill (SDI, Australia), Filtek Bulk Fill Flow (3MESPE, Germany), Filtek Bulk Fill Sculptable (3MESPE, Germany), Surefil SDR + (Dentsply, Germany), Tetric EvoFlow Bulk Fill (Ivoclar-Vivadent, Liechtenstein), Admira Fusion (Voco, Germany), X-tra Fil (Voco, Germany), X-tra Base (Voco, Germany), Opus (FGM, Brazil), and two conventional resins - Filtek Z350XT (3MESPE, Germany) and Filtek Z350 Flow (3MESPE, Germany).

For energy-dispersive X-ray spectroscopy (EDS), DC, and VMH analyses, specimens obtained from each material, measuring $5 \mathrm{~mm}$ in diameter and 4 $\mathrm{mm}$ in thickness, were prepared. In order to prevent oxygen inhibition, a transparent polyester strip was placed on the top and bottom of the mold, and resins were inserted and photopolymerized with a LED device (KaVo Poly Wireless, KaVo - Brazil) in compliance with the manufacturer's instructions (Table 1). The light-curing unit was calibrated at $1,200 \mathrm{nW} / \mathrm{cm}^{2}$ and irradiance was measured using a radiometer. All specimens were stored in distilled water at $37^{\circ} \mathrm{C}$ for $24 \mathrm{~h}$ prior to testing. For the linear CTE, the samples measured $10 \mathrm{~mm}$ in diameter and $4 \mathrm{~mm}$ in thickness. 
Table 1. Test materials and manufacturer's information.

\begin{tabular}{|c|c|c|c|c|c|c|}
\hline Code & $\begin{array}{l}\text { Material and } \\
\text { manufactured batch no }\end{array}$ & Monomers & Fillers & $\begin{array}{l}\text { Photoinitiators/ } \\
\text { Coinitiators }\end{array}$ & Shade & $\begin{array}{c}\text { Thickness (mm)/Curing time } \\
\text { and light intensity }\end{array}$ \\
\hline$A B F$ & $\begin{array}{l}\text { Aura bulk fill (SDI, São } \\
\text { Paulo, Brazil) - } 150931\end{array}$ & n.i & n.i & n.i & $U$ & $\begin{array}{c}4 \mathrm{~mm} / 20 \mathrm{~s} \geq 1,000 \mathrm{~mW} / \\
\mathrm{cm}^{2} \text { (LED) or } 2 \times 20 \text { s (halogen } \\
\text { light). }\end{array}$ \\
\hline \multirow[t]{3}{*}{ FBFF } & $\begin{array}{c}\text { Filtek Bulk Fill Flow }^{\mathrm{TM}} \\
\text { (3M/ESPE St. Paul, MN, } \\
\text { USA) - N735392 }\end{array}$ & $\begin{array}{l}\text { Bis-GMA, } \\
\text { UDMA } \\
\text { Bis-EMA }\end{array}$ & $\begin{array}{c}\text { Ytterbium trifluoride } \\
\text { Zirconia/silica }-64 \text { wt } \%, \\
42.5 \text { vol }\end{array}$ & n.i & A2 & $\begin{array}{c}4 \mathrm{~mm} / 20 \mathrm{~s} \geq 1,000 \mathrm{~mW} / \mathrm{cm}^{2} \\
\text { or } 40 \mathrm{~s} 550-1,000 \mathrm{~mW} / \mathrm{cm}^{2} \\
\text { (halogen or LED) }\end{array}$ \\
\hline & & Procrylat & & & & \\
\hline & $\begin{array}{l}\text { Filtek Bulk'M Fill } \\
\text { Sculptable }\end{array}$ & $\begin{array}{l}\text { Bis-GMA, } \\
\text { AUDMA }\end{array}$ & & & & \\
\hline FBFS & $\begin{array}{l}\text { (3M/ESPE St. Paul, MN, } \\
\text { USA) - N686825 }\end{array}$ & UDMA & $\begin{array}{l}\text { Silica, zirconia, ytterbium } \\
\text { trifluoride, zirconia/silica } \\
\quad-76.5 w+\%, 58.4 \mathrm{vol}\end{array}$ & n.i & A2 & $\begin{array}{c}4 \mathrm{~mm} / 20 \mathrm{~s} \geq 1,000 \mathrm{~mW} / \mathrm{cm}^{2} \\
\text { (LED) or } 40 \mathrm{~s} 550-1000 \mathrm{~mW} / \\
\mathrm{cm}^{2} \text { (halogen light). }\end{array}$ \\
\hline
\end{tabular}

DDDMA

\begin{tabular}{|c|c|c|c|c|c|c|}
\hline $\mathrm{SDR}^{+}$ & $\begin{array}{l}\text { SureFil }{ }^{\circledR} \text { SDR }{ }^{+} \text {Flow }{ }^{\text {TM }} \\
\text { (DENTSPLY Petropolis, } \\
\text { Brazil) - } 160613\end{array}$ & $\begin{array}{l}\text { Modified } \\
\text { UDMA } \\
\text { EBPADMA } \\
\text { TEGDMA }\end{array}$ & $\begin{array}{c}\text { Barium and strontium } \\
\text { fluoro-alumino silicate } \\
\text { glasses - } 68 \mathrm{wt} \%, 44 \\
\text { vol } \%\end{array}$ & $\begin{array}{c}\text { Camphoroquinone } \\
\text { (CQ), BHT, UV } \\
\text { Stabilizer, Titanium } \\
\text { dioxide, iron } \\
\text { oxide pigments, } \\
\text { Fluorescing agent }\end{array}$ & $U$ & $\begin{array}{c}4 \mathrm{~mm} / 20 \mathrm{~s} 500-1,000 \mathrm{~mW} / \\
\mathrm{cm}^{2} \text { (LED and halogen) or } \\
10 \mathrm{~s} \text { (high-power lights). }\end{array}$ \\
\hline $\mathrm{AF}$ & $\begin{array}{l}\text { Admira Fusion x-tra } \\
\text { (VOCO Cuxhaven, } \\
\text { Germany) - } 1619518\end{array}$ & n.i & Inorganic fillers - 84wt\% & n.i & $U$ & $\begin{array}{l}4 \mathrm{~mm} / 20 \mathrm{~s} \geq 800 \mathrm{~mW} / \mathrm{cm}^{2} \\
\text { or } 40 \mathrm{~s} 500-800 \mathrm{~mW} / \mathrm{cm}^{2}\end{array}$ \\
\hline TEF & $\begin{array}{c}\text { Tetric EvoFlow Bulk Fill } \\
\text { (IVOCLAR VIVADENT } \\
\text { Amherst, } \\
\text { NY, USA) - U4 } 1169\end{array}$ & $\begin{array}{l}\text { Bis-GMA } \\
\text { Bis-EMA } \\
\text { UDMA }\end{array}$ & $\begin{array}{c}\text { Prepolymer fillers, } \\
\text { barium glass filler, } \\
\text { ytterbium fluoride and } \\
\text { spherical mixed oxide } \\
\text { fillers - } 62.5 \mathrm{wt} \%, 60 \\
\text { vol\% }\end{array}$ & $\begin{array}{l}\text { Camphorquinone } \\
\text { / amine Highly } \\
\text { reactive, patented } \\
\text { Ivocerin light initiator }\end{array}$ & $U$ & $4 \mathrm{~mm} / 20 \mathrm{~s} \geq 600 \mathrm{~mW} / \mathrm{cm}^{2}$ \\
\hline XTB & $\begin{array}{c}\text { X-tra Base (VOCO } \\
\text { Cuxhaven, Germany) - } \\
1621410\end{array}$ & n.i & $\begin{array}{c}\text { Inorganic fillers - } 75 \mathrm{w}+\%, \\
58 \text { vol\% }\end{array}$ & n.i & $U$ & $\begin{array}{l}4 \mathrm{~mm} / 10 \mathrm{~s} \geq 800 \mathrm{~mW} / \mathrm{cm}^{2} \\
\text { or } 20 \mathrm{~s} 500-800 \mathrm{~mW} / \mathrm{cm}^{2}\end{array}$ \\
\hline XTF & $\begin{array}{c}\text { X-tra Fill (VOCO } \\
\text { Cuxhaven, Germany) - } \\
1547611\end{array}$ & $\begin{array}{l}\text { Bis-GMA, } \\
\text { UDMA, } \\
\text { TEGDMA }\end{array}$ & $\begin{array}{c}\text { Inorganic fillers - } 86 \mathrm{wt} \% \\
70,1 \text { vol\% }\end{array}$ & n.i & $U$ & $\begin{array}{l}4 \mathrm{~mm} / 10 \mathrm{~s} \geq 800 \mathrm{~mW} / \mathrm{cm}^{2} \\
\text { or } 20 \mathrm{~s} 500-800 \mathrm{~mW} / \mathrm{cm}^{2}\end{array}$ \\
\hline Opus & $\begin{array}{l}\text { OPUS Bulk Fill Flow } \\
\text { (FGM Joinville - SC - } \\
\text { Brazil) - } 010816\end{array}$ & $\begin{array}{c}\text { Monomers } \\
\text { Urethane } \\
\text { dimethacrylate }\end{array}$ & Silicon dioxide (silica) & Camphorquinone & $\mathrm{Al}$ & $4 \mathrm{~mm} / 20 \mathrm{~s} \geq 450 \mathrm{~mW} / \mathrm{cm}^{2}$ \\
\hline
\end{tabular}

Continue 


\begin{tabular}{|c|c|c|c|c|c|c|}
\hline Z350F & $\begin{array}{l}\text { Filtek Z350 XT Flow }{ }^{\top M} \\
\text { universal restorative (3M } \\
\text { ESPE, St Paul, MN, USA) } \\
\quad-1605300512\end{array}$ & $\begin{array}{l}\text { BisEMA, } \\
\text { TEGDMA, } \\
\text { Procrylat } \mathrm{K}\end{array}$ & $\begin{array}{c}\text { Terbium and silica } \\
\text { fluoride } \\
\text { Silica / zirconia - } 65 \mathrm{w}+\% \text {, } \\
46 \text { vol } \%\end{array}$ & n.i & A2 & $\begin{array}{c}2 \mathrm{~mm} / 20 \mathrm{~s} 500-1,000 \mathrm{~mW} / \\
\mathrm{cm}^{2} \text { (LED and halogen) or } \\
10 \mathrm{~s} \text { (high-power lights). }\end{array}$ \\
\hline Z350 & $\begin{array}{c}\text { Filtek }^{\text {TM }} \text { Z350 XT } \\
\text { universal restorative (3M } \\
\text { ESPE, St Paul, MN, USA) } \\
-236236\end{array}$ & $\begin{array}{l}\text { UDMA, } \\
\text { BisEMA, } \\
\text { BisGMA, } \\
\text { TEGDMA, } \\
\text { PEGDMA }\end{array}$ & $\begin{array}{c}\text { Silica, zirconia, silica/ } \\
\text { zirconia }-72.5 \mathrm{w}+\%, \\
55.6 \text { vol\% }\end{array}$ & n.i & A2 & $\begin{array}{c}2 \mathrm{~mm} / 20 \mathrm{~s} \geq 400 \mathrm{~mW} / \mathrm{cm}^{2} \\
\text { (LED or halogen). }\end{array}$ \\
\hline
\end{tabular}

UDMA: urethane dimethacrylate, Bis-GMA: bisphenol A glycidyl methacrylate, Bis-EMA: ethoxylated bisphenol A glycol dimethacrylate, EBADMA: ethoxylated bisphenol A dimethacrylate, EDMAB: ethyl-4-dimethylaminobenzoate, DDDMA: 1,12-dodecane-DMA, TEGDMA:

Tetraethyleneglycol Dimethacrylate, PEGDMA: Poly(ethylene glycol) diacrylate. n.i: without manufacturer's information.

\section{Physicomechanical analysis}

\section{Identification of chemical elements in EDS}

The specimens were cleaned in an ultrasonic tank at $50^{\circ} \mathrm{C}$ for $5 \mathrm{~min}$ and then washed with distilled water and dried at room temperature $(30 \mathrm{~min})$. Afterwards, the samples $(n=3)$ were subjected to EDS (PHENOM pro X, Scientific ANACOM) to determine the chemical elements present at the point of the beam incidence. Three areas of each sample were selected for reading. The samples received no surface treatment for preview.

\section{Degree of conversion}

The non-polymerized material and the top and bottom surfaces of the photopolymerized samples $(n=3)$ were analyzed after $24 \mathrm{~h}$ by an FTIR spectrophotometer (Perkin Elmer, Norwalk, CT, USA) equipped with attenuated total reflection (ATR) wavelength between 4,000 and $650 \mathrm{~nm}$. Thirty-two scans were performed on each sample $(n=3)$ with a resolution of $2.0 \mathrm{~cm}^{-1}$. Peak heights of $1,637 \mathrm{~cm}^{-1}$ (double bonds of aliphatic carbon) and 1,608 $\mathrm{cm}^{-1}$ (double bonds of aromatic carbon) were measured using the normalized baseline method on the same equipment and the \% DC values of the monomers were determined by the following equation:

$\% D C=\left[1-\left(\frac{\frac{1637 \mathrm{~cm}^{-1}}{1608 \mathrm{~cm}^{-1}} \text { Peak height cure }}{\frac{1637 \mathrm{~cm}^{-1}}{1608 \mathrm{~cm}^{-1}} \text { Peak height uncure }}\right)\right] \times 100$

\section{Vickers microhardness}

Although some studies indicate Knoop microhardness as the most suitable method for testing composite resins, others advocate the use of VMH. The Knoop indenter penetrates less deeply. Especially in composite resins with irregular surfaces, because of the presence of charge particles, VMH allows obtaining more reliable results, despite possible interference from elastic deformation. The VMH test was performed using a digital microdurometer (FM 700, Future Tech Corp., Equilam, Tokyo, Japan) with a load of $50 \mathrm{kgf}$ applied for $15 \mathrm{~s}$. Three readings were performed at the top and bottom $(4 \mathrm{~mm})$, obtaining a final mean for each sample $(n=5)$. The length of the diagonals ( $\mathrm{d} 1$ and $\mathrm{d} 2$ ) left by the indenter was measured digitally under a light microscope coupled to the microdurometer.

\section{Thermal analyses}

\section{Thermogravimetric analysis}

TGA was performed in a thermogravimetric analyzer (SDT 2960 -TA Instruments). As polymerization parameters, polymerized and non-polymerized samples $(10 \mathrm{mg}, \mathrm{n}=3)$ were heated from $25^{\circ} \mathrm{C}$ to $600^{\circ} \mathrm{C}$, considering a heating rate of $10^{\circ} \mathrm{C} / \mathrm{min}$ and a nitrogen flow of $200 \mathrm{~mL} / \mathrm{min}$. Proteus software was used to generate TGA curves and calculate the percentage of mass loss, the amount (\%) of residues after decomposition, and thermal stability. The extrapolated onset decomposition temperature, according to ASTM E794-06 and E793-06 (American Society for Testing and Materials), was determined for each material. 


\section{Differential scanning calorimetry}

For the DSC analysis (DSC, Perkin Elmer), the polymerized samples $(10 \mathrm{mg}, \mathrm{n}=3)$ were subjected to a heat flow ranging from $25^{\circ} \mathrm{C}$ to $45^{\circ} \mathrm{C}$, at a heating rate of $10^{\circ} \mathrm{C} / \mathrm{min}^{-1}$, in a nitrogen atmosphere. An identical and empty aluminum capsule was used as reference. The data provided in graphs were analyzed using the software (NETZSCH-TA4_5ProteusSoftware,Netzsch, D). The glass transition temperature $(\mathrm{Tg})$, the melting and degradation temperatures, and enthalpy $(\Delta \mathrm{H})$ were obtained.

\section{Linear thermal expansion analysis}

The analyses were performed using a differential horizontal dilatometer (NETZCH DIL 402 C, Selb, Germany) with $3 \%$ of accuracy. The CTE and the linear CTE were measured in the temperature range of 27 to $100^{\circ} \mathrm{C}$ with variation of $4^{\circ} \mathrm{C} / \mathrm{min}$. The values were obtained by the following equations:

$$
\Delta L-L_{0} \cdot a \cdot \Delta T \quad \mathrm{CTE}_{\text {Linear }}=\frac{\Delta L}{L_{0} \cdot \Delta T}
$$

Where,

$\Delta \mathrm{L}$ : linear dilation;

$\mathrm{L}_{0}$ : initial length;

$\alpha$ : linear coefficient of expansion;

$\Delta \mathrm{T}$ : temperature variation.

CTE: coefficient of thermal expansion

Before the experimental test, the equipment was calibrated with silica and an initial scan was performed.

\section{Statistical analysis}

Statistical analysis was performed using Statistical Software 2007 (Utah, USA), SPSS version 23. In addition to standard descriptive statistics (mean and standard deviation), the F-test (ANOVA) with post-hoc Tukey's test was used when the variances were equal, or Tamhane test when the hypothesis of variance was rejected. VMH and DC were analyzed by the Wilcoxon test for paired data, Kruskal-Wallis test with paired comparisons between DC and VMH, and by means of the Mann-Whitney test. Regression analysis was performed to investigate the relationship between \% DC and VMH according to the evaluated surfaces; \% DC and Tg; weight \% of residues/load particles after TGA and microhardness, and between these and \% DC. Regression analysis was carried out to investigate the relationship between $\mathrm{Tg}$ and onset temperature, mass loss, and final residue quantity. The level of statistical significance was set at 0.05 .

\section{Results}

\section{Physicomechanical analysis}

\section{Identification of chemical elements (EDS)}

EDS analysis showed that silica (Si) was the predominant compound in all materials. It was possible to identify components such as $\mathrm{Ba}, \mathrm{Zr}, \mathrm{Al}$, $\mathrm{F}, \mathrm{Ca}$, and Sr, among others (Figure 1).

\section{Degree of conversion and Vickers microhardness}

The resins showed no significant difference in \% DC and VMH. Statistical differences were observed only among materials (Table 2). AF, FBFS, and XTF resins showed the highest DC on the top surface $(99 \%$, $98 \%$, and $90 \%$, respectively), while Z350F obtained a lower conversion (57\%). On the bottom surface, ABF presented lower conversion (20\%). Regarding microhardness, Z350 and XTF presented significantly higher values than the other resins (Table 2). A low positive correlation was found between DC and $\mathrm{VMH}$, according to the evaluated surfaces. Data also show a moderate correlation $(\mathrm{r}=0.64)$ between the weight $\%$ of residues/load particles after TGA and microhardness and a low correlation $(\mathrm{r}=0.49)$ between these and DC (Figure 2). The coefficient of correlation between $\%$ DC and Tg was low $(r=-0.37)$.

\section{Thermal analysis}

\section{TGA and DSC}

TGA results are shown in Table 3. The final weight percent of the residues/load particles ranged from 60.1 (Z350F) to 87.1 (AF) in the non-polymerized material and from 33.4 (FBFF) to 87.0 (AF) in the polymerized material. Mass loss $(\mathrm{m} \%)$ was higher in Z350F and FBFF, without polymerization and with polymerization, respectively, and FBFF showed a greater mass loss $(57.7 \%)$ before reaching the peak of the initial decomposition temperature. The other materials presented similar mass loss to each other. 

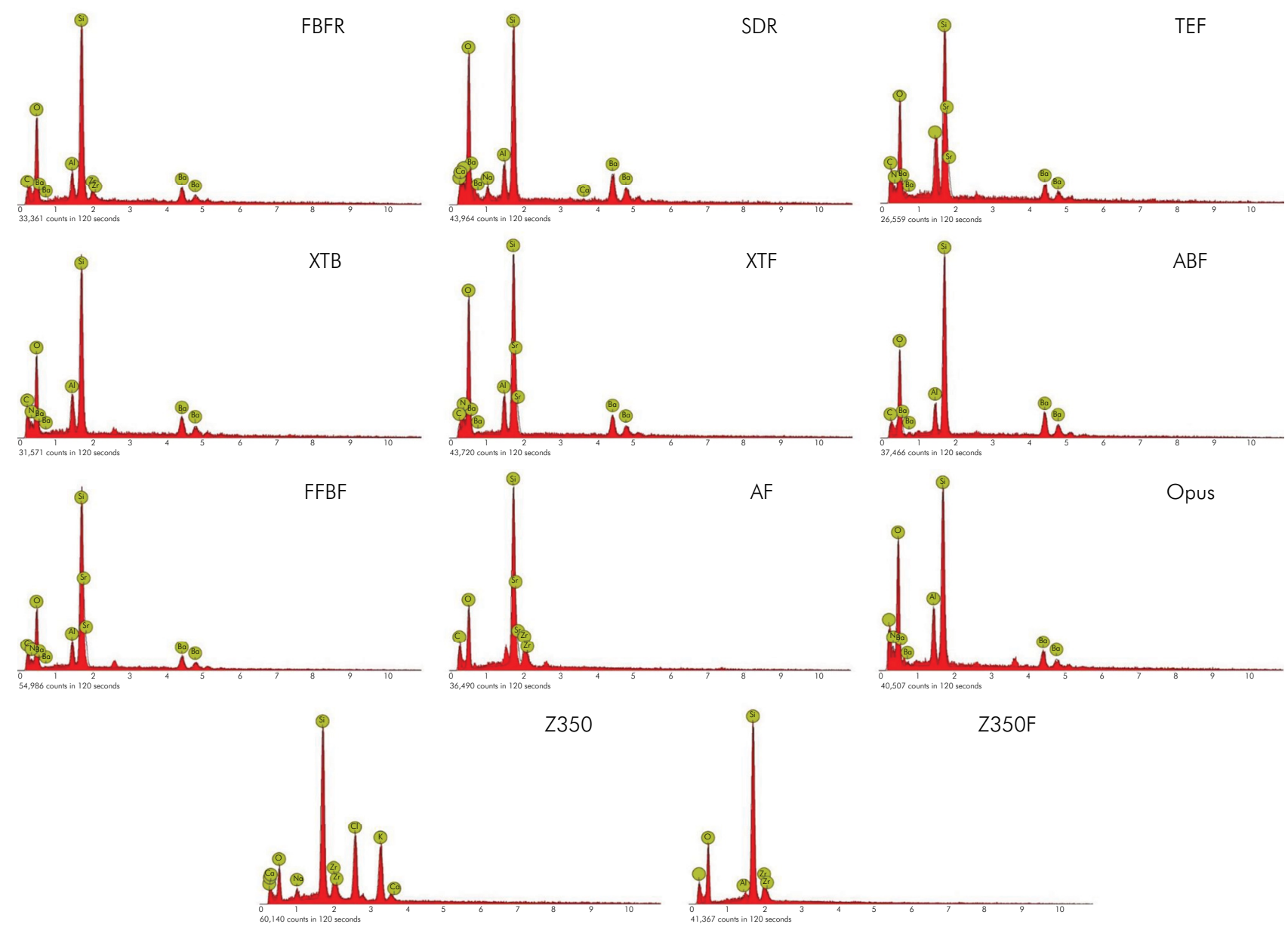

Figure 1. Representative EDS images of bulk-fill dental composites. Chemical elements present in each sample, obtained by EDS analysis.

Table 2. Mean \pm standard deviation of the degree of conversion and Vickers microhardness according to the material and to the polymerization side of the specimen.

\begin{tabular}{|c|c|c|c|c|c|c|}
\hline \multirow{2}{*}{ Material } & \multicolumn{3}{|c|}{ Degree of conversion (\% DC) } & \multicolumn{3}{|c|}{ VMH (Kg/f) } \\
\hline & Top & Bottom & & Top & Bottom & \\
\hline AF & $99.0(0.51)^{(\mathrm{A})}$ & $58.97(15.3)^{(\mathrm{ACGH})}$ & & $92.92(14.5)^{(A)}$ & $87.67(12.0)^{(A D)}$ & \\
\hline$A B F$ & $77.1(1.08)^{(B)}$ & $20.70(7.19)^{(B)}$ & & $76.33(8.26)^{(A D)}$ & $63.41(9.26)($ (EFHI) & \\
\hline FBFS & $98.0(0.20)^{(A C)}$ & $56.17(2.01)^{(\mathrm{AB})}$ & & $80.73(3.28)^{(A)}$ & $74.81(3.97)^{(\mathrm{AB})}$ & \\
\hline $\mathrm{SDR}^{+}$ & $85.9(1.74)^{(B D)}$ & $66.70(1.84)$ (CEIJ) & & $74.21(10.3)^{(B D)}$ & $69.07(11.5)^{(B E)}$ & \\
\hline TEF & $74.3(1.22)^{(\mathrm{E})}$ & $64.33(2.14)^{(A C I)}$ & $p^{(1)}>0.05$ & $59.49(11.0)^{(C)}$ & $52.63(9.52)^{(C)}$ & $\mathrm{p}^{(1)}>0.05$ \\
\hline Opus & $72.2(4.33)(E)$ & $67.13(2.60)$ (CDEIL) & & $62.27(6.42)(c)$ & $55.15(9.04){ }^{(\mathrm{CH})}$ & \\
\hline XTB & $75.0(0.40)^{(E)}$ & $68.77(1.83)^{(F I)}$ & & $87.32(7.88)^{(C)}$ & 70.05 (1 1.4) (B1) & \\
\hline XTF & $90.5(3.31)^{(C D)}$ & $75.37(2.75)^{(\mathrm{FL})}$ & & $152.87(14.0)^{(E)}$ & $145.69(8.70)^{(G)}$ & \\
\hline Z350 & $64.6(1.35)^{(\mathrm{F})}$ & $58.73(2.96)$ (AगM) & & $112.02(4.60)^{(E)}$ & $104.00(6.02)^{(D G)}$ & \\
\hline Z350F & $57.3(0.91)^{(F)}$ & $54.77(0.50)$ (BGM) & & $60.37(4.15)^{(B D)}$ & $50.76(6.29)^{(C)}$ & \\
\hline \multirow[t]{2}{*}{ FBFF } & $72.3(4.22)^{(E)}$ & $67.53(1.80)^{(H I L)}$ & & $59.49(11.0)^{(C)}$ & $52.63(9.52)^{(C)}$ & \\
\hline & $\mathrm{p}^{(2)}=0.001^{*}$ & $p^{(2)}=0.008^{*}$ & & $\mathrm{p}^{(2)}<0.001^{*}$ & $\mathrm{p}^{(2)}<0.001^{*}$ & \\
\hline
\end{tabular}

$\left({ }^{*}\right)$ Significant difference at 5\%. (1) By the Wilcoxon test for paired data. (2) By the Kruskal-Wallis test with paired comparisons. (3) By the MannWhitney test. P.s. Different letters in parentheses indicate a significant difference between the corresponding materials. 

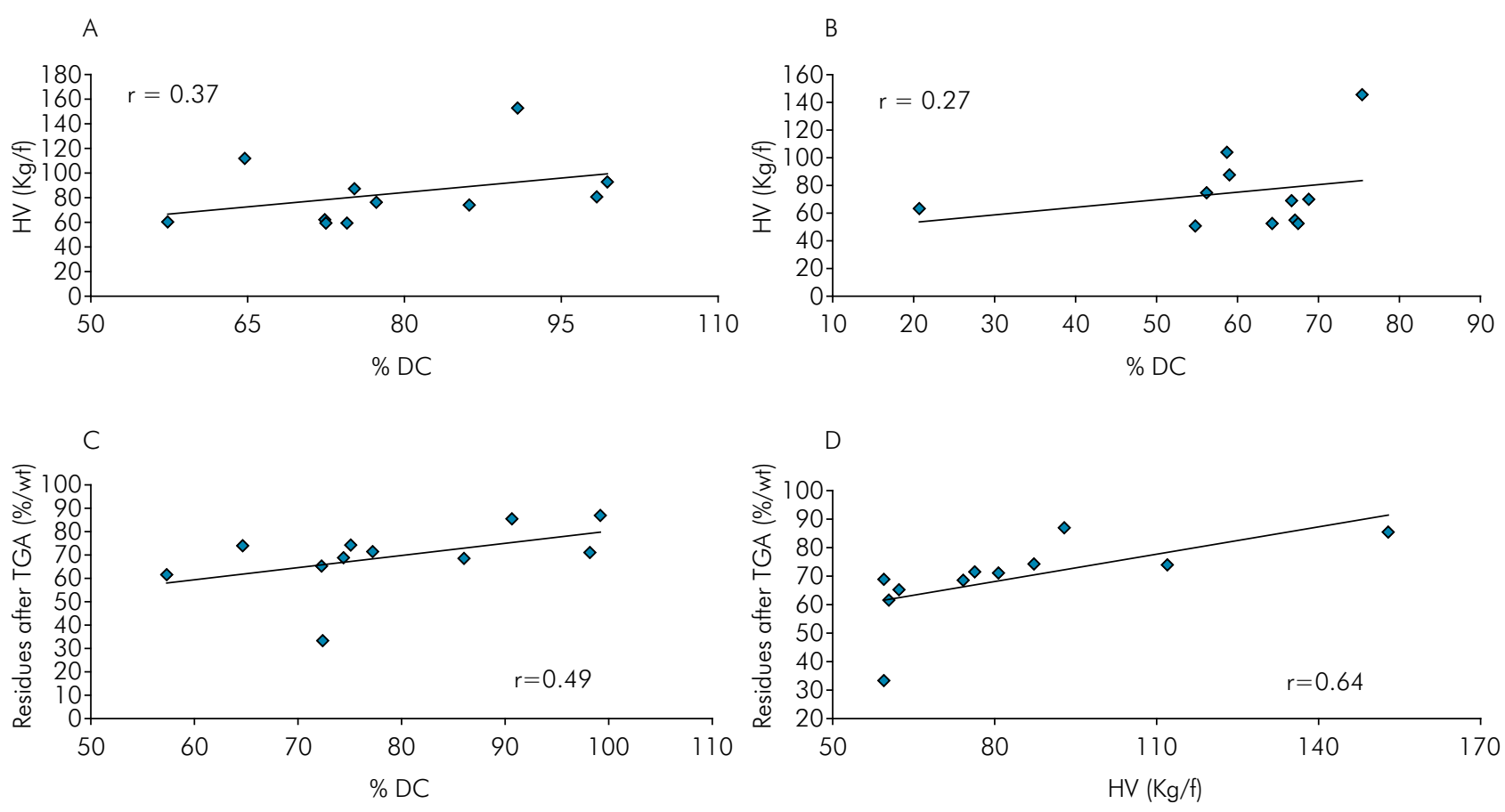

Figure 2. Correlation between degree of conversion and Vickers microhardness, considering the polymerized side: top (A) and bottom (B); between the \% of residues, in weight, of the polymerized sample after TGA, and the degree of conversion (C) and microhardness (D).

Table 3. Mean values of mass loss (\%), residues (\%), and onset decomposition temperature of each resin - TGA.

\begin{tabular}{|c|c|c|c|c|c|c|c|c|c|c|c|}
\hline \multirow{2}{*}{ TGA } & \multicolumn{11}{|c|}{ Composite resins } \\
\hline & $\mathrm{ABF}$ & Z350 & $\mathrm{AF}$ & TEF & $\mathrm{SDR}^{+}$ & FBFS & XTB & XTF & Opus & Z350F & FBFF \\
\hline \multicolumn{12}{|l|}{ Non-Polymerized } \\
\hline Mass loss (\%) & 27.5 & 25.6 & 13.0 & 29.3 & 31.5 & 25.6 & 25.0 & 15.3 & 35.7 & 40.0 & 39.2 \\
\hline Residues (\%) & 72.4 & 74.2 & 87.1 & 70.7 & 68.5 & 76.2 & 75.0 & 84.2 & 64.3 & 60.1 & 62.7 \\
\hline Onset decomposition temperature $\left({ }^{\circ} \mathrm{C}\right)$ & 172.8 & 361.2 & 396.0 & 303.6 & 263.8 & 300.1 & 196.9 & 201.6 & 336.7 & 300.9 & 341.7 \\
\hline \multicolumn{12}{|l|}{ Polymerized } \\
\hline Mass loss (\%) & 28.6 & 26.0 & 12.8 & 31.2 & 31.5 & 28.9 & 25.8 & 14.5 & 34.7 & 38.5 & 66.7 \\
\hline Residues (\%) & 71.5 & 74.0 & 87.0 & 68.9 & 68.6 & 71.1 & 74.3 & 85.5 & 65.3 & 61.6 & 33.4 \\
\hline Onset decomposition temperature $\left({ }^{\circ} \mathrm{C}\right)$ & 346.6 & 368.3 & 418.9 & 344.6 & 413.6 & 358.5 & 344.7 & 416.6 & 405.8 & 355.1 & 475.7 \\
\hline
\end{tabular}

Table 4 shows the mean $\mathrm{Tg}$, enthalpy, and melting and degradation temperatures for the polymerized resins. The composites had similar $\mathrm{Tg}$, with no statistically significant difference. There was a low correlation between $\mathrm{Tg}$ and onset temperature $(\mathrm{r}=-0.35)$, mass loss $(r=0.1)$, and final residue quantity $(r=-0.1)$.

\section{Linear thermal expansion}

Figure 3 (A) shows the relative variation of $\Delta \mathrm{L} / \mathrm{L}$ for each resin. The XTF resin exhibited lower dimensional variation and lower linear CTE. From $27^{\circ} \mathrm{C}$, the CTE $\left(10^{-6} /{ }^{\circ} \mathrm{C}^{-1}\right)$ of the resins was as follows, in decreasing order (mean $\pm \mathrm{SD}$ ): 
Table 4. Mean glass transition temperature $(\mathrm{Tg}), \Delta \mathrm{H}$, melting and degradation temperatures.

\begin{tabular}{|c|c|c|c|c|c|c|c|c|c|c|c|}
\hline \multirow{2}{*}{ DSC } & \multicolumn{11}{|c|}{ Composite resins } \\
\hline & $\mathrm{ABF}$ & Z350 & $\mathrm{AF}$ & TEF & $\mathrm{SDR}^{+}$ & FBFS & XTB & XTF & Opus & Z350F & FBFF \\
\hline \multicolumn{12}{|l|}{ Polymerized } \\
\hline $\operatorname{Tg}$ & 54.64 & 55.52 & 50.71 & 56.57 & 54.54 & 54.78 & 58.17 & 57.07 & 54.46 & 55.05 & 55.05 \\
\hline Melting temperature & 237.0 & 196.0 & 252.4 & 184.2 & 296.3 & 197.6 & 267.1 & - & - & 189.5 & - \\
\hline$\Delta \mathrm{H}(\mathrm{J} / \mathrm{g})$ & 0.33 & 0.79 & 0.56 & 0.76 & 2.74 & 1.34 & 1.25 & 1.69 & 0.66 & 0.15 & 1.50 \\
\hline Degradation temperature & 424.5 & - & 383.3 & - & - & 394.0 & 392.7 & 420.2 & 395.4 & 416.8 & 431.0 \\
\hline
\end{tabular}

$(-)$ it was not possible to determine it.

Z350F (37.1 \pm 21.4$), \mathrm{ABF}(22.5 \pm 11.4), \mathrm{FBFF}(22.2 \pm$ 3.9), TEF (20.2 \pm 5.8$), \operatorname{AF}(19.5 \pm 4.1)$, Opus (19.0 \pm 6.2), Z350 (17.5 \pm 5.0$)$, FBFS (16.5 \pm 3.0$)$, XTB (15.8 $\pm 2.2), \mathrm{SDR}+(15.0 \pm 3.2)$, and XTF $(10.3 \pm 2.8)$, without statistically significant difference $(\mathrm{p}>$ 0.05 ) (Figure 3B). The linear regression analysis showed a moderate negative correlation $(\mathrm{r}=-0.56)$ between the amount of load particles and CTE (Figure 3C).

\section{Discussion}

This study evaluated the thermal and physicomechanical behaviors of some commercial resins to identify chemical elements and to determine the \% DC and VMH, thermal stability, degradation behavior, glass transition temperature, and enthalpy, in addition to the linear CTE. Some manufacturers did not provide information on the composition of the inorganic part of the composites used in this study (Table 1), so it was necessary to carry out the EDS analysis, for understanding that the type of load particle influences the thermal behavior of composites before, during, and after polymerization. Composites filled with quartz or silicon nitride/silica exhibit higher thermal diffusivity, while composites containing radiopaque fillers, such as barium or strontium, exhibit lower thermal diffusivity. ${ }^{11}$ In this study, silica (Si) was the component with the highest percentage among all materials. This may be justified by the fact that the inorganic components were not evaluated separately from the organic ones, and silica is present in the silane binding agent. Other components such as $\mathrm{Ba}, \mathrm{Zr}, \mathrm{Al}, \mathrm{Y}, \mathrm{Ca}$, and $\mathrm{Sr}$ have also been identified. Zirconia and silica peaks correspond to zirconia-silica clusters or to silicate particles present in the composition of these composites and have the potential to transfer more heat during polymerization. Ba and $Y$ are related to radiopacity properties..$^{12}$ Some of the composites used (Table 1) also contain agglomerated particles of $100 \mathrm{~nm}$ of ytterbium trifluoride $(\mathrm{YbF} 3)$ to increase their radiopacity. ${ }^{13}$ Additionally, the amount of load particles is related to the improvement in the physicomechanical properties of the composites. ${ }^{14}$

The first null hypothesis related to DC and $\mathrm{VMH}$ was rejected, since a significant difference was found between the materials. The DC of all analyzed materials did not show significant differences between the evaluated surfaces (top and bottom), but the conversion values on the lower surface were smaller, indicating incomplete conversion of double carbon bonds. This is due to the chemical nature of the monomers which, upon initiating the polymerization process, promote the formation of a cross-linked solid polymer within a few seconds, increasing viscosity throughout the organic matrix, thereby preventing complete polymerization. Unreacted molecules may be present as residual monomers or as pending groups of the polymer network. When present as residual monomers, they act as plasticizers, reducing mechanical strength and increasing water uptake. ${ }^{15}$ 
A

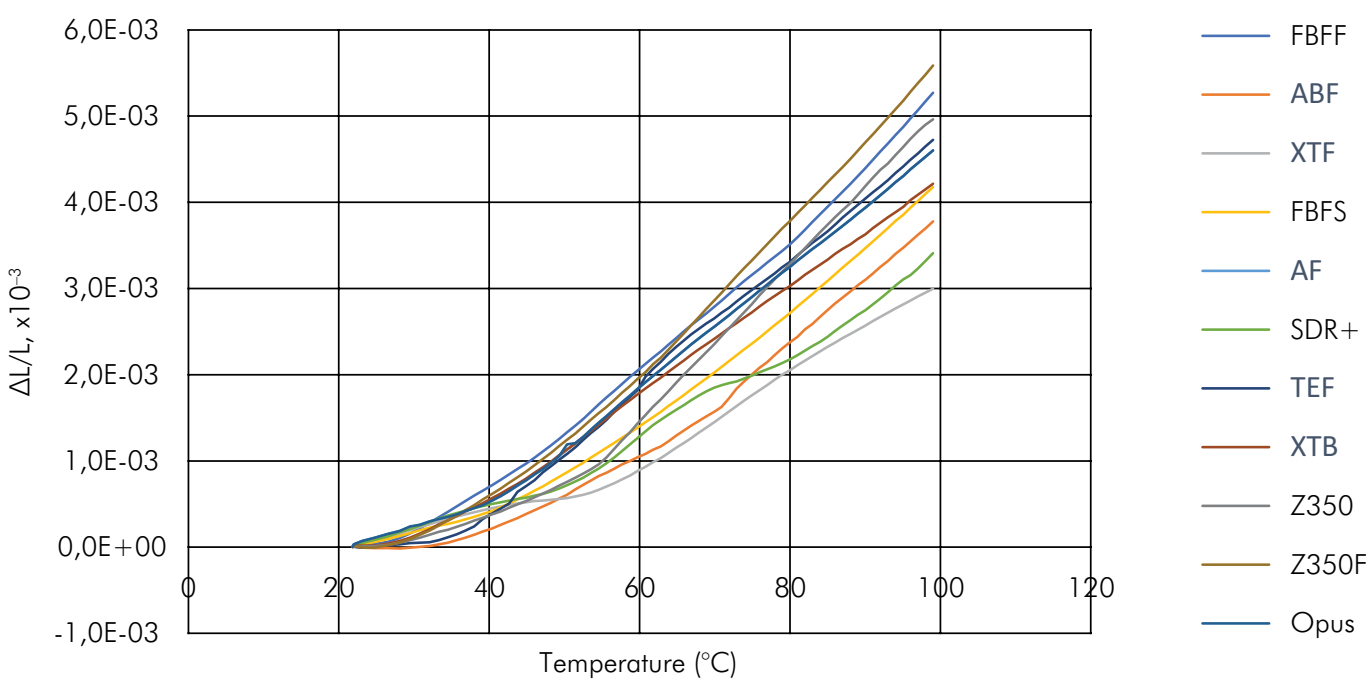

B

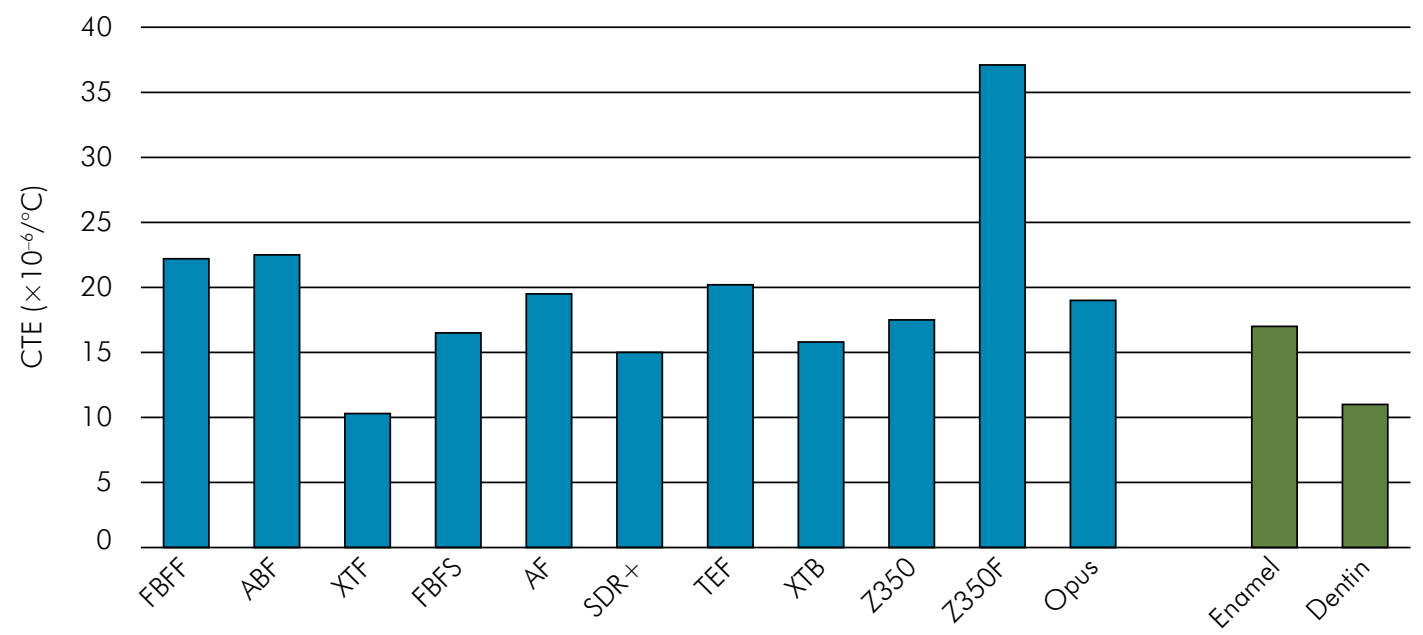

C

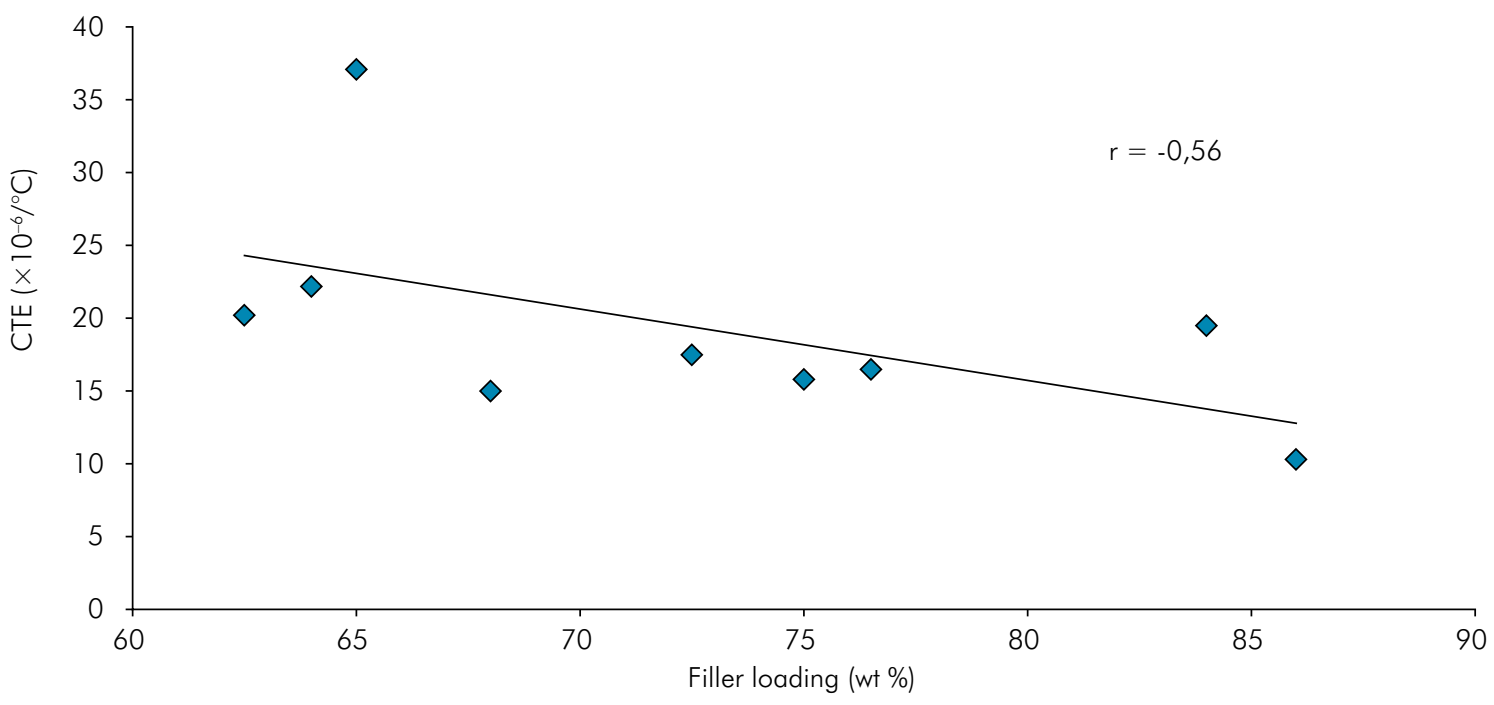

Figure 3. (A) Relative dimensional variation $(\Delta \mathrm{L} / \mathrm{L})$ of composite resin, $(B)$ thermal expansion, $(C)$ linear correlation between $C T E$ and filler loading of the dental composites. 
In addition, the structural arrangement and spatial distribution of the polymer chains, oligomers and monomers, is directly related to the physicomechanical properties of these materials..$^{16}$ On the other hand, Czasch and Ilie ${ }^{17}$ report that the evaluation of the DC of monomers to polymers in bulk-fill resins would not be a relevant factor for the evaluation of their mechanical properties, because a higher DC in a composite resin with several components does not necessarily mean that better mechanical properties will be obtained. In this study, it should be highlighted that all resins obtained DC values, at the top and bottom, above what is clinically recommended (> 55\%), according to Alshali et al., ${ }^{18}$ except for AFB, which presented a $56.4 \%$ reduction at the bottom. Other studies ${ }^{19,20}$ also obtained good results for the DC of bulk-fill resins with a thickness of $4 \mathrm{~mm}$. The higher translucency, the modifications in the photoinitiator system, and the incorporation of load particles, which function as "microscopic springs" in bulk-fill resins, compared to the conventional ones used in these studies (Z350 and Z350F), may explain the higher DC values.

In this study, the bulk-fill resins presented lower microhardness in relation to restorative resins, in agreement with the findings of Czasch et al., ${ }^{17}$ Flury etal., ${ }^{21}$ and Tekin et al. ${ }^{22}$ The low percentage of load particles may be related to the obtained data. Among flow resins, XTB presented better VMH than did the other materials, which leads us to believe that the obtained data are related to the loading content of each material, corroborating the findings of Leprince et al., ${ }^{14}$ Zorzin et al., ${ }^{19}$ and AlShaafi et al. ${ }^{23}$ Our data showed no significant reduction in microhardness in relation to the polymerized side.

Since these materials are broadly indicated for posterior tooth restoration both in direct and semidirect techniques, the heating method before and after polymerization has been widely employed to achieve further monomer conversion. ${ }^{24}$ The heat supplied to the polymerized material increases the degree of polymerization because of the presence of free radicals, which remain in the material for days or even months, depending on the density of the cross-linked bonds and on the storage temperature..$^{25}$ The heat supply before polymerization, on the other hand, assists in the conversion of the monomers in the composites used in direct form, besides increasing fluidity and promoting better adaptation of the cavity walls. ${ }^{26}$ However, it is necessary to know how they behave when subjected to high levels of heat. Therefore, the influence of temperature on the stability and on the linear CTE of these composites was evaluated using TGA, DSC, and dilatometry.

The data obtained by TGA showed that the extrapolated onset temperature in the polymerized material ranged from 344.6 (TEF) to 475.7 (FBFF), indicating variations in the thermal stability and degree of cross-linking density established during the formation of the polymer network, demonstrating that the temperature in the non-polymerized material was lower, which led to the rejection of the second hypothesis. According to Teshima et al., ${ }^{27}$ main mass losses occur in the temperature range of 370 to $440{ }^{\circ} \mathrm{C}$, with the release of propionic acid, fernic groups, methacrylic acid, HEMA, and TEGDMA, due to polymer matrix decomposition, which is in line with our results. The highest losses observed in this study occurred in this temperature range. As for the values of the obtained residues, which correspond to the weight percent of the load particles, the information given by the manufacturers was similar for most resins. FBFF, Z350F, and XTF presented lower percentage values than those reported by the manufacturer. This is probably due to the thermal degradation of silane or the evaporation of some inorganic components, or because some manufacturers determine the percentage of the inorganic filler prior to the silanization process, while others include it in their calculations. ${ }^{28}$ The polymerized FBFF resin showed a marked discrepancy in the load content when compared to the manufacturers' data and the same was observed without polymerization, which is probably due to the volatilization of unreacted monomers or to other degradation processes. All materials presented more than one stage of thermal decomposition, a phenomenon that occurs because of thermal scission of the polymer matrix during heating, which is characteristic of UDMA-based materials. ${ }^{29}$

The composites showed similar Tg values in DSC, with no statistically significant difference. Studies report that the $\mathrm{Tg}$ of direct resin composites is related to monomer composition, type and concentration of load particles, 
and cross-linking density, the latter of which depends on the DC and is responsible for the determination of the physicomechanical properties of a polymer. ${ }^{30} \mathrm{The} \mathrm{Tg}$ of polymerized samples can be correlated with $\mathrm{DC}$, since materials with a higher DC present greater formation of cross-links between the chains, requiring higher temperatures. However, a low correlation between DC and Tg was found. The DSC results obtained in this study were similar to those obtained in previous studies. ${ }^{31,32,22}$

Linear CTE and dilation were evaluated using a horizontal dilatometer. The resins exhibited linear CTE similar to that of the dental structure, for enamel and dentin: $17\left(\times 10^{-6} /{ }^{\circ} \mathrm{C}\right)$ and $11\left(\times 10^{-6} /{ }^{\circ} \mathrm{C}\right)$, respectively, ${ }^{33}$ which is clinically favorable to maintain the integrity of the tooth/restoration interface. However, Raue et al. ${ }^{34}$ point out the need to evaluate the CTE of the enamel associated with the material to be used. The highest coefficient was observed in Z350F (37.1) and the lowest one in XTF (10.3), with no statistically significant difference $(\mathrm{p}>0.05)$, so the third hypothesis was also rejected. Considering that the resin matrix of these composites is similar to the differences found between them, this must be related to the inorganic content, corroborating the literature data when CTE is related to the amount of load particles. ${ }^{35,36}$ The percentage of XTF particles (86 $\mathrm{wt} \%$ and $70.1 \mathrm{vol} \%)$ is higher than that of other resins and Z350F ( $65 \mathrm{wt} \%$ and $42 \% \mathrm{vol}$ ), despite having more particles by weight than TEF ( $62.5 \mathrm{wt} \%$ and $60 \mathrm{wt} \% \mathrm{vol}$ ), it had a smaller amount in volume, so it presented a higher CTE. However, a moderate negative correlation $(r=-0.56)$ was found between CTE and the load particles. Park et al. ${ }^{35}$ and Alnazzawi et al. ${ }^{37}$ report a high negative correlation between these two variables. Therefore, the larger the inorganic portion of the resin, the smaller the expansion, then its CTE is about $0.5 \sim 6\left(\times 10^{-6} /{ }^{\circ} \mathrm{C}\right)$ while that of the organic matrix is approximately $110 \sim 190\left(\times 10^{-6} /{ }^{\circ} \mathrm{C}\right) .{ }^{35}$ Besides, composites with more resin matrix and fewer load particles can generate more heat during polymerization, causing damage to the pulp and to the underlying tissues..$^{13}$ The loading percentage should be one of the fundamental criteria for the choice of the restorative material, in order to avoid problems such as microleakage, secondary caries, loss of adhesive material, and staining of restorative resins, because of the expansion and contraction of the resinous material. When analyzing the dilatometry results of $\Delta \mathrm{L} / \mathrm{L}$ dependencies, a similar size variation was observed for all samples (Figure 3A). At the same time, $\Delta \mathrm{L} / \mathrm{L}$ variations were in the same range, coinciding with the CTE data, denoting a certain similarity in the composition of the resins.

\section{Conclusion}

In this study, composites with conventional and bulk-fill resins were evaluated, presenting some differences in their composition and formulation, which influenced the obtained results. Thus, the conclusions can be summarized as follows:

a. The DC of the evaluated composites was higher than what is expected for commercial composites, except for $\mathrm{ABF}$, on the lower surface. The DC of all resins was higher on the top surface, but with no statistical difference.

b. The restorative bulk-fill resins presented superficial VMH results on the top and bottom surfaces, similarly to those of flow resins, except for XTF, which had higher values. VMH values were lower for all resins on the bottom surface.

c. TGA showed similar mass loss between resins and waste/charge particles, similar to those reported by the manufacturers.

d. The $\mathrm{Tg}$ of all resins was within the temperature range of 50 to $60{ }^{\circ} \mathrm{C}$, in agreement with literature data.

e. The linear CTE of the resins was acceptable once it approached the linear CTE of the dental structure, except for Z350F.

f. Silica was the predominant inorganic component in all composites.

g. There was a low positive correlation between DC and $\mathrm{VMH}$, according to the evaluated surface; a moderate correlation between the weight \% of residues/load particles after TGA and VMH; and a low correlation between these and DC.

\section{Acknowledgements}

The authors gratefully acknowledge the Federal University of Campina Grande (UFCG), Paraíba, Brazil, for its technical support. The authors also express their special thanks to all members of CERTBIO for their contribution to this work. 
- Physicomechanical and thermal analysis of bulk-fill and conventional composites

\section{References}

1. Bicalho AA, Tantbiroin D, Versluis A, Soares CJ. Effect of occlusal loading and mechanical properties of resin composite on stress generated in posterior restorations. Am J Dent. 2014 Jun;27(3):129-33.

2. Ilie N, Bucuta S, Draenert M. Bulk-fill resin-based composites: an in vitro assessment of their mechanical performance. Oper Dent. 2013 Nov-Dec;38(6):618-25. https://doi.org/10.2341/12-395-L

3. Hirata R, Kabbach W, de Andrade OS, Bonfante EA, Giannini M, Coelho PG. Bulk Fill composites: an anatomic sculpting technique. J Esthet Restor Dent. 2015 Nov-Dec;27(6):335-43. https://doi.org/10.1111/jerd.12159

4. Kim RJ, Kim YJ, Choi NS, Lee IB. Polymerization shrinkage, modulus, and shrinkage stress related to tooth-restoration interfacial debonding in bulk-fill composites. J Dent. 2015 Apr;43(4):430-9. https://doi.org/10.1016/i.jdent.2015.02.002

5. Rosatto CM, Bicalho AA, Veríssimo C, Bragança GF, Rodrigues MP, Tantbirojn D, et al. Mechanical properties, shrinkage stress, cuspal strain and fracture resistance of molars restored with bulk-fill composites and incremental filling technique. J Dent. 2015 Dec;43(12):1519-28. https://doi.org/10.1016/i.jdent.2015.09.007

6. Tauböck TT, Tarle Z, Marovic D, Attin T. Pre-heating of high-viscosity bulk-fill resin composites: effects on shrinkage force and monomer conversion. J Dent. 2015 Nov;43(11):1358-64. https://doi.org/10.1016/i.jdent.2015.07.014

7. Furness A, Tadros MY, Looney SW, Rueggeberg FA. Effect of bulk/incremental fill on internal gap formation of bulk-fill composites. J Dent. 2014 Apr;42(4):439-49. https://doi.org/10.1016/i.jdent.2014.01.005

8. Abovelleil H, Pradelle N, Villat C, Attik N, Colon P, Grosgogeat B. Comparison of mechanical properties of a new fiber reinforced composite and bulk filling composites. Restor Dent Endod. 2015 Nov;40(4):262-70. https://doi.org/10.5395/rde.2015.40.4.262

9. Ferracane JL, Condon JR. Post-cure heat treatments for composites: properties and fractography. Dent Mater. 1992 Sep;8(5):290-5. https://doi.org/10.1016/0109-5641(92)90102-I

10. Veloso SR, Lemos CA, Moraes SL, Vasconcelos BCE, Pellizzer EP, Monteiro GQM. Clinical performance of bulk-fill and conventional resin composite restorations in posterior teeth: a systematic review and meta-analysis. Clin Oral Investig. 2018. https://doi.org/10.1007/s00784-018-2429-7

11. Watts DC, McAndrew R, Lloyd CH. Thermal diffusivity of composite restorative materials. J Dent Res. 1987 Oct;66(10):1576-8. https://doi.org/10.1177/00220345870660101201

12. Lachowski KM, Botta SB, Lascala CA, Matos AB, Sobral MA. Study of the radio-opacity of base and liner dental materials using a digital radiography system. Dentomaxillofac Radiol. 2013;42(2):20120153. https://doi.org/10.1259/dmfr.20120153

13. Kim MJ, Kim RJ, Ferracane J, Lee IB. Thermographic analysis of the effect of composite type, layering method, and curing light on the temperature rise of photo-cured composites in tooth cavities. Dent Mater. 2017 Oct;33(10):e373-83. https://doi.org/10.1016/i.dental.2017.07.007

14. Leprince JG, Palin WM, Vanacker J, Sabbagh J, Devaux J, Leloup G. Physico-mechanical characteristics of commercially available bulkfill composites. J Dent. 2014 Aug;42(8):993-1000. https://doi.org/10.1016/i.jdent.2014.05.009

15. Castro FL, Campos BB, Bruno KF, Reges RV. Temperature and curing time affect composite sorption and solubility. J Appl Oral Sci. 2013 Mar-Apr;21(2):157-62. https://doi.org/10.1590/1678-7757201302298

16. Atmadja G, Bryant RW. Some factors influencing the depth of cure of visible light-activated composite resins. Aust Dent J. 1990 Jun;35(3):213-8. https://doi.org/10.1111/j.1834-7819.1990.tb05394.x

17. Czasch P, Ilie N. In vitro comparison of mechanical properties and degree of cure of bulk fill composites. Clin Oral Investig. 2013 Jan;17(1):227-35. https://doi.org/10.1007/s00784-012-0702-8

18. Alshali RZ, Silikas N, Satterthwaite JD. Degree of conversion of bulk-fill compared to conventional resin-composites at two time intervals. Dent Mater. 2013 Sep;29(9):e213-7. https://doi.org/10.1016/i.dental.2013.05.011

19. Zorzin J, Maier E, Harre S, Fey T, Belli R, Lohbauer U, et al. Bulk-fill resin composites: polymerization properties and extended light curing. Dent Mater. 2015 Mar;31(3):293-301. https://doi.org/10.1016/i.dental.2014.12.010

20. Par M, Gamulin O, Marovic D, Klaric E, Tarle Z. Raman spectroscopic assessment of degree of conversion of bulk-fill resin compositeschanges at 24 hours post cure. Oper Dent. 2015 May-Jun;40(3):E92-101. https://doi.org/10.2341/14-091-L

21. Flury S, Peutzfeldt A, Lussi A. Influence of increment thickness on microhardness and dentin bond strength of bulk fill resin composites. Dent Mater. 2014 Oct;30(10):1104-12. https://doi.org/10.1016/i.dental.2014.07.001

22. Tekin TH, Kantürk Figen A, Yılmaz Atalı P, Coşkuner Filiz B, Pişkin MB. Full in-vitro analyses of new-generation bulk fill dental composites cured by halogen light. Mater Sci Eng C. 2017 Aug;77:436-45. https://doi.org/10.1016/i.msec.2017.03.251

23. AlShaafi MM, Haenel T, Sullivan B, Labrie D, Alqahtani MQ, Price RB. Effect of a broad-spectrum LED curing light on the Knoop microhardness of four posterior resin based composites at 2, 4 and 6-mm depths. J Dent. 2016 Feb;45:14-8. https://doi.org/10.1016/j.jdent.2015.11.004 
24. Ferracane JL, Condon JR. Post-cure heat treatments for composites: properties and fractography. Dent Mater. 1992 Sep;8(5):290-5. https://doi.org/10.1016/0109-5641(92)90102-I DUPLICATA DA 9

25. Zhu ST, Tian Y, Hamielec AE, Eaton DR. Radical concentrations in free radical copolymerization of MMA/EGDMA. Polymer (Guildf). 1990;31(1):154-9. https://doi.org/10.1016/0032-3861(90)90368-9

26. Blalock JS, Holmes RG, Rueggeberg FA. Effect of temperature on unpolymerized composite resin film thickness. J Prosthet Dent. 2006 Dec;96(6):424-32. https://doi.org/10.1016/i.prosdent.2006.09.022

27. Teshima WNY, Ikeda A, Kawahara T, okazaki M, Nahara Y. Thermal degradation of photo-polymerized Bis-GMA/TEGDMA-based dental resins. Polymer \& Degrad Stab. 2004;84(1):167-72.

28. Sabbagh J, Ryelandt L, Bachérius L, Biebuyck JJ, Vreven J, Lambrechts $P$, et al. Characterization of the inorganic fraction of resin composites. J Oral Rehabil. 2004 Nov;31(11):1090-101. https://doi.org/10.1111/j.1365-2842.2004.01352.x

29. Achilias DS, Karabela MM, Sideridou ID. Thermal degradation of light-cured dimethacrylate resins: Part I. Isoconversional kinetic analysis. Thermochim Acta. 2008;472(1-2):74-83. https://doi.org/10.1016/i.tca.2008.02.004

30. Almaroof A, Niazi SA, Rojo L, Mannocci F, Deb S. Evaluation of dental adhesive systems incorporating an antibacterial monomer eugenyl methacrylate (EgMA) for endodontic restorations. Dent Mater. 2017 May;33(5):e239-54. https://doi.org/10.1016/i.dental.2017.01.016

31. Sideridou I, Achilias DS, Kyrikou E. Thermal expansion characteristics of light-cured dental resins and resin composites. Biomaterials. 2004 Jul;25(15):3087-97. https://doi.org/10.1016/j.biomaterials.2003.09.078

32. Engelhardt F, Hahnel S, Preis V, Rosentritt M. Comparison of flowable bulk-fill and flowable resin-based composites: an in vitro analysis. Clin Oral Investig. 2016 Nov;20(8):2123-30. https://doi.org/10.1007/s00784-015-1700-4

33. Xu HC, Liu WY, Wang T. Measurement of thermal expansion coefficient of human teeth. Aust Dent J. 1989 Dec;34(6):530-5. https://doi.org/10.1111/j.1834-7819.1989.tb04660.x

34. Rave L, Klein H. Calculation of anisotropic properties of dental enamel from synchrotron data. J Synchrotron Radiat. 2011 Jul;18(Pt 4):550-6. https://doi.org/10.1107/S0909049511011071

35. Park JK, Hur B, Ko CC, García-Godoy F, Kim HI, Kwon YH. Effect of light-curing units on the thermal expansion of resin nanocomposites. Am J Dent. 2010 Dec;23(6):331-4.

36. Rajan G, Shouha P, Ellakwa A, Bhowmik K, Xi J, Prusty G. Evaluation of the physical properties of dental resin composites using optical fiber sensing technology. Dent Mater. 2016 Sep;32(9):1113-23. https://doi.org/10.1016/i.dental.2016.06.015

37. Alnazzawi A, Watts DC. Simultaneous determination of polymerization shrinkage, exotherm and thermal expansion coefficient for dental resin-composites. Dent Mater. 2012 Dec;28(12):1240-9. https://doi.org/10.1016/i.dental.2012.09.004 